\title{
A comparative analysis of the antecedents and consequences of employee satisfaction for urban and rural healthcare workers in KwaZulu-Natal province, South Africa
}

\begin{tabular}{|c|c|}
\hline \multicolumn{2}{|c|}{$\begin{array}{l}\text { Authors: } \\
\text { Brian Tawana }{ }^{1} \\
\text { Nicolene E. Barkhuizen }^{2} \\
\text { Yvonne du Plessis }^{1}\end{array}$} \\
\hline \multicolumn{2}{|c|}{$\begin{array}{l}\text { Affiliations: } \\
\text { 'NWU Business School, } \\
\text { North-West University, } \\
\text { Mahikeng, South Africa }\end{array}$} \\
\hline \multicolumn{2}{|c|}{$\begin{array}{l}{ }^{2} \text { Global Innovative Forefront } \\
\text { Talent Research Niche Area, } \\
\text { North-West University, } \\
\text { Mahikeng, South Africa }\end{array}$} \\
\hline \multicolumn{2}{|c|}{$\begin{array}{l}\text { Corresponding author: } \\
\text { Nicolene Barkhuizen, } \\
\text { nbarkhuizen@sbs.ac.za }\end{array}$} \\
\hline \multicolumn{2}{|c|}{$\begin{array}{l}\text { Dates: } \\
\text { Received: } 23 \text { May } 2018 \\
\text { Accepted: } 29 \text { May } 2019 \\
\text { Published: } 29 \text { Nov. } 2019\end{array}$} \\
\hline \multicolumn{2}{|c|}{$\begin{array}{l}\text { How to cite this article: } \\
\text { Tawana, B., Barkhuizen, N.E., } \\
\text { \& Du Plessis, Y. (2019). A } \\
\text { comparative analysis of the } \\
\text { antecedents and } \\
\text { consequences of employee } \\
\text { satisfaction for urban and } \\
\text { rural healthcare workers in } \\
\text { KwaZulu-Natal province, } \\
\text { South Africa. SA Journal of } \\
\text { Human Resource } \\
\text { Management/SA Tydskrif vir } \\
\text { Menslikehulpbronbestuur, } \\
\text { 17(0), a1080. https://doi.org/ } \\
\text { 10.4102/sajhrm.v17i0.1080 }\end{array}$} \\
\hline \multicolumn{2}{|c|}{$\begin{array}{l}\text { Copyright: } \\
\text { (c) 2019. The Authors. } \\
\text { Licensee: AOSIS. This work } \\
\text { is licensed under the } \\
\text { Creative Commons } \\
\text { Attribution License. }\end{array}$} \\
\hline \multicolumn{2}{|l|}{ Read onlin } \\
\hline 口isq & $\begin{array}{l}\text { Scan this QR } \\
\text { code with your } \\
\text { smart phone or } \\
\text { mobile device } \\
\text { to read online. }\end{array}$ \\
\hline
\end{tabular}

Authors:

Brian Tawana ${ }^{1}$

Nicolene E. Barkhuizen ${ }^{2}$

Yvonne du Plessis ${ }^{1}$

Affiliations:

North-West University,

${ }^{2}$ Global Innovative Forefront Talent Research Niche Area, North-West University,

Corresponding author: Nicolene Barkhuizen,

Dates:

Received: 23 May 2018

Accepted: 29 May 2019

How to cite this article: Tawana, B., Barkhuizen, N.E. \& Du Plessis, Y. (2019). A antecedents and

consequences of employee satisfaction for urban and rural healthcare workers in KwaZulu-Natal province,

South Africa. SA Journal of

Menslikehulpbronbestuur,

17(0), a1080. https://doi.org/

Copyright:

(c) 2019. The Authors. Licensee: AOSIS. This work

is licensed under the

Creative Commons
Orientation: The South African healthcare industry is facing significant challenges to retain quality healthcare professionals to deliver services in rural areas.

Research purpose: The main purpose of this study was to compare the antecedents and consequences of employee satisfaction for healthcare professionals in urban and rural areas to establish if there are distinguishing factors that can better inform human resource (HR) management to improve job satisfaction and service delivery. KwaZulu-Natal province was chosen because of its number and proximity of rural and urban healthcare facilities.

Motivation for the study: A holistic perspective, focusing on both urban and rural South African settings, on how the healthcare sector can retain healthcare workers through employee satisfaction and service delivery is lacking.

Research approach/design and method: The research design for the study is a mixed-method sequential design. A quantitative survey using a structured questionnaire inclusive of the constructs such as work environment, work satisfaction, job satisfaction, employee retention and service quality was administered to a sample of urban and rural healthcare professionals in KwaZulu-Natal $(N=405)$. In addition, the researchers conducted three focus group discussions $(N=28)$.

Main findings: The quantitative results showed that urban and rural sample groups differed significantly in terms of their satisfaction with work duties, compensation, career development, service delivery and turnover intentions. Communalism was found to play a major role in retention and quality of service delivery of healthcare professionals in rural settings.

Practical/managerial implications: The findings of this study require from management to understand the differential factors between urban and rural settings in service quality and staff retention. Human resource practitioners are encouraged to understand the differentiators of job satisfaction and service delivery in an urban and rural context and develop conducive work environments that allow healthcare workers to execute their tasks effectively.

Contribution/value-add: This study provides a unique perspective of the antecedents and outcomes of employee satisfaction for both urban and rural healthcare sector workers and indicates that context is important.

Keywords: career development; employee satisfaction; healthcare; retention; service delivery.

\section{Introduction}

The local and global mobility of healthcare professionals presents major challenges to the South African healthcare system. Recent statistics by the International Labour Organization (ILO) show that South Africa has less than one doctor and nurse per citizen (ILO, 2018). The migration of healthcare workers is currently fuelled by factors such as poor living and working conditions in rural areas (Haskins, Phakathi, Grant, \& Horwood, 2017), community recognition (Ngilangwa \& Mgomella, 2018), increased job demands and workloads (Jenkins, Gunst, Blitz, \& Coetzee, 2017) and financial well-being (Coustas, 2019). Moreover, the migration of healthcare workers results in a shortage of skills (Clemens, 2007), which in turn constrains the delivery of services in public health institutions (George, Atujuna, \& Gow, 2013). 
Recently, Pillay (2017) highlighted the need to investigate, plan and implement effective measures to recruit and retain more healthcare workers such as nurses to the healthcare profession in South Africa. Employee satisfaction emerged as an important attitudinal variable that has the potential to reduce employee turnover, absenteeism, tardiness and health setbacks as a result of stressful work conditions in the healthcare sector (Tinu \& Adeniji, 2015). Singh (2017) is of the opinion that employees' stress level and satisfaction with their jobs are the primary factors that affect the quality of work and productivity. Job satisfaction has been reported as an important mediator and moderator variable in the relationship between work-related factors (i.e. organisational support and quality of work-life) and outcome variables in the healthcare sector (i.e. service quality and retention) (Goetz et al., 2015; Kim \& Han, 2012).

The main objective of this research is to compare the antecedents and outcomes of employee satisfaction for healthcare professionals in urban and rural areas in KwaZuluNatal (KZN). A number of studies have investigated satisfaction amongst healthcare professionals; however, the broader concepts of employee satisfaction and service quality within the context of urban and rural healthcare settings have not been described in the literature. The assumption, based on findings from previous research, is that the rural healthcare sector provides different challenges to employee satisfaction and service quality than the urban sector. Given the noticeable lack of studies investigating and distinguishing employee satisfaction and service quality of clinical and nonclinical healthcare practitioners in both urban and rural public health settings (hospitals and clinics) in South Africa, the present study will attempt to address this gap in the body of knowledge. KwaZulu-Natal with its unique urban-rural divide pertaining to public healthcare facilities provides an environment in which such research could be conducted. The findings should assist in clarifying the urban-rural situation regarding employment of professional healthcare staff and support the talent management process in attracting and retaining professionals in the public health sector in $\mathrm{KZN}$ and other areas in South Africa.

The populations of both rural and urban areas are growing in South Africa (Stats SA, 2015), which are associated with increased demands for healthcare. KwaZulu-Natal has the highest prevalence of HIV in South Africa (George et al., 2013). This alone suggests an increased demand for healthcare services, irrespective of other diseases that burden the healthcare system. The uniqueness of KZN, compared to other provinces in South Africa, is its extreme urban and rural context in which healthcare has to be provided, which could also affect the employee satisfaction and mobility of professional healthcare workers between rural and urban facilities.

\section{Literature review}

The literature review will focus on the antecedents and consequences of employee satisfaction for healthcare workers in both urban and rural settings. We identify certain work- related factors such as general work duties, leadership and supervision, professional development and safety as potential contributors to employee satisfaction. We identify retention and service quality as outcomes of healthcare worker satisfaction in this study.

\section{Antecedents of employee satisfaction: Work-related factors}

Employee satisfaction is one of the most studied areas in organisational psychology. Aziri (2001) defines employee satisfaction as the attitudes and feelings of people about their job and its numerous aspects, and the degree to which the job is liked or disliked by the worker. Heathfield (2016) uses the term 'employee satisfaction' to describe whether employees are contented, happy and fulfilling their work needs. For the purpose of this research, we define employee satisfaction as a multi-dimensional construct that consists of job satisfaction and general work satisfaction.

A great deal of research has been devoted towards understanding the predictors of job satisfaction in the healthcare industry. A study by Gormley (2003) showed that factors such as professional independence, leadership styles and behaviour, organisational climate, perceived role conflict and ambiguity and organisational characteristics had a significant impact on the job satisfaction of nurses. Parvin and Kabir (2011) found that remuneration, job efficiency, supervisions and collegial relationships are the most critical factors that enhance the job satisfaction of workers in pharmaceutical industry.

A comparative study by Campbell and Ebuehi (2011) showed that healthcare workers in rural and urban areas had different sources of job satisfaction. The study pointed out that urban workers derived their satisfaction from the availability of career development opportunities and the availability of materials and equipment. Job satisfaction for rural workers was dependent on community recognition for their work and improved staff relations. Both sample groups were dissatisfied with a lack of management support, client relationships and a lack of in-service training.

Coward, Hogan, Duncan and Felsen (2017) found no significant differences in job satisfaction between hospital nurses in urban and rural areas. The study however pointed out that factors such as race and personal income of nurses, perception of nurses about supervisor interest in their career aspirations, the length of time that nurses intended to stay at the time of their hiring and their current intentions to leave were significant predictors of the job satisfaction of nurses.

Grujicic, Jovovic-Bata, Radjen and Sipetic-Grujicic (2016) found that urban health professionals were significantly more satisfied with their jobs than their rural counterparts. Grujicic et al. (2016) further maintained that job satisfaction of health workers can be improved by providing better income, more supervisor support, awards for good performance, promotion and advancement opportunities, 
employment security and interpersonal relationships. Thus, this study proposes the following hypothesis:

H1: Significant differences exist between urban and rural healthcare workers based on the antecedents of employee satisfaction

\section{The consequences of employee satisfaction}

\section{Retention as an outcome of employee satisfaction}

Factors relating to the relationship between job satisfaction and turnover intentions of healthcare staff in urban and rural areas are many and varied. Bhattacharya and Ramachandran (2015) found that healthcare professionals in urban areas were more likely to quit their jobs because of dissatisfaction with the availability of technology and training in the use of available technology. For rural healthcare workers, work dissatisfaction, career development, workload and management played a significant role in their intention to quit their jobs (Bonenberger, Aikins, Akweongo, \& Wyss, 2014). A study by Adegoke, Atiyaye, Abubakar, Auta and Aboda (2015) found that rural midwife dissatisfaction with a lack of established career ladder, available promotion opportunities, safety and accommodation, and the degree to which they were fairly paid for their work efforts were main contributors to their turnover intentions.

Ogbuabor, Okoronkwo, Uzochukwu and Onwujekwe (2016) concluded that the implementation of effective financial and non-financial incentives is an important driver of job satisfaction and retention for public sector workers. A study by Nkomozana (2017) emphasised the redress of inadequate supervisory practices, change in healthcare manager's supervision paradigm and recognition of supervisor's inadequate supervisory skills as important factors to combat high staff turnover in the healthcare sector. Thus, we propose the following hypothesis:

H2: A significant negative relationship exists between the employee satisfaction (consisting of general work and job satisfaction) and turnover intentions of urban and rural healthcare workers.

\section{Service quality as an outcome of employee satisfaction}

According to Deriba, Sinke, Ereso and Badacho (2017), job satisfaction of healthcare workers is important for employee performance, quality patience care and patient satisfaction. Quality service delivery is defined as the ability of the service provider to meet or exceed customers' needs and expectations (Bakar, Akgun, \& Assaf, 2007). Ronen and Pilskin (2006) posit that quality service is achieved through a quality process, which is achieved when the employees and managers are part of the process design and control. A study by Goetz et al. (2015) found that an integrated quality management system provides a good opportunity to strengthen the recruitment and retention of healthcare staff required for quality care.

Whelan, Davies, Walsh and Bourke (2010) mentioned that it is important that patients have confidence in a healthcare service provider. Peltier and Dahl (2009) found a direct and positive relationship between the satisfaction of employees and the quality of the patient experience in a major urban hospital. Research by Aron (2015) showed a positive correlation between nurses' job satisfaction and the quality of care they deliver in a small urban hospital. The study of Aron (2015) further showed that workload, staff scheduling and stress were the factors that affect the delivery of quality care mostly. A study by Mohase and Khumalo (2014) found that healthcare workers in rural areas were in agreement that job satisfaction improves their productivity and performance in the sense that job satisfaction affects the way they meet their targets. Thus, the following hypothesis is proposed:

H3: There would be significant positive relationship between the employee satisfaction (consisting of general work and job satisfaction) of healthcare workers in urban and rural areas and their orientation towards quality service care.

\section{Research design Research approach}

This research followed a sequential approach whereby the quantitative data were first collected by using a survey, followed by the collection of qualitative data using focus groups. Johnson, Onwuegbuzie and Turner (2007) define a quantitative-dominant mixed-methods approach as:

$[A]$ type of mixed research in which one relies on a quantitative view of the research process, while concurrently recognizing that the addition of qualitative data and approaches are likely to benefit most research projects. (p. 124)

Two important research paradigms for this mixed-methods approach were functionalism (quantitative phase) and interpretivism (qualitative phase). The functionalist paradigm is appropriate for replication in theory-testing and refinement. Data are gathered in such a way that a different researcher could replicate the same process under similar conditions and obtain the same results (Shah \& Coley, 2006). Shah and Coley (2006) further stated that in the interpretive paradigm, the goal is to ensure representativeness of the data and interpretation thereof. A cross-sectional research design was followed whereby data were collected from the respondents at one point in time. Cross-sectional research is ideally suited to test for cause and effect relationships between variables (Field, 2018).

\section{Research method}

\section{Research participants}

The sample for the quantitative study was grouped into two categories based on location (i.e. rural or urban). Two hospitals and two clinics were purposively selected from each of the target districts. A total of 450 questionnaires were distributed of which 405 questionnaires were completed by the healthcare professionals, giving a response rate of $90 \%$.

The respondents in this sample were predominantly men in both the urban $(80.2 \%)$ and rural $(73.5 \%)$ areas. Most of the participants in both areas were married (urban: 50\%; rural: 
49.4\%). The respondents indicated their primary home language as indigenous (IziZulu) (urban: 90.5\%; rural: 86.4\%) in both areas. In the urban areas, $28.4 \%$ of the respondents fell within the age group of 20-29 years, while in the rural areas the age category, 30-39 years, had the highest percentage $(30.9 \%)$ of respondents. The classification of respondents according to the number of years in their current job revealed that the majority of respondents in both urban (57.2\%) and rural $(60.5 \%)$ areas fell within the category of $0-5$ years. Both groups (urban: $42.4 \%$; rural: $43.8 \%$ ) had $0-5$ years of work experience. Most respondents in the urban areas indicated that they were employed as midwives (46.2\%). In the rural areas, the majority of the respondents $(63.0 \%)$ reported that they were in 'other' occupations (pharmacist, dentist, radiographer, etc.). Both the Antenatal care and Maternity/Labour and delivery specialties were represented by $55(22.6 \%)$ respondents in the urban areas. In the rural areas, Casualty/Medical/Surgical was represented by $84(51.9 \%)$ respondents. Both urban $(64.6 \%)$ and rural $(74.1 \%)$ participants were employed in hospitals.

The participants $(N=28)$ of the focus group session were an equal number of clinical and non-clinical staff members and representative of both rural and urban areas. Most of the participants were aged between 30 and 39 years (43\%) and employed as nurses (29\%) and occupational therapists (14\%). The participants were primarily employed between 0 and 10 years in their occupation (40\%).

\section{Measuring instruments}

A structured questionnaire was developed to measure the following - work environment, work satisfaction, employee satisfaction, employee retention and service quality - of health professionals in KZN. The questionnaire development was informed by the literature. A description of each of the measures is presented below.

Work environment: The work environment measure consisted of 19 items and measured five facet factors: Work Duties, Supervision, Compensation, Professional Development and Safety. Responses were collected on a five-point Likert scale ranging from $1=$ strongly disagree to $5=$ strongly agree.

General work satisfaction: This consisted of three items and measured responses on items such as 'If I could choose the career again, I would make the same decision' and 'In general, I am satisfied with my work'. Reponses were collected on a five-point Likert scale ranging from 1 = strongly disagree to 5 = strongly agree.

Employee satisfaction: This measure consisted of six items and measured the participants' responses on items such as 'Overall, you are satisfied with your job' and 'You would recommend working in a job like yours at your facility to a friend'. Reponses were collected on a five-point Likert scale ranging from $1=$ strongly disagree to $5=$ strongly agree.

Employee retention: This measure consisted of eight items and measured items such as 'In the past year, you have considered stopping your work as a [health practitioner],or doing something else other than work as a[health practitioner]' and 'In the coming year, you plan to stop working at this health facility'. Reponses were collected on a five-point Likert scale ranging from $1=$ strongly disagree to $5=$ strongly agree .

Service quality: This measure consisted of six items and measured items such as 'How would you rate the quality of care at this health facility?' The participants had the option to rate facilities such as family planning services, delivery care and postpartum care. Reponses were collected on a five-point Likert scale ranging from $1=$ poor to $5=$ very good.

The questionnaire was piloted for refinement (see DeMaio, Rothgeb, \& Hess, 1998) and checking of important issues, such as time taken to complete the questionnaire, as well as adequacy and appropriateness of the questions. Time considerations were very important, as the survey required the involvement of health professionals during working hours. Fifteen questionnaires were completed in the piloting phase.

The qualitative data were gathered through three focus group discussion sessions to clarify data from quantitative analysis and obtain deeper insights into the rural-urban retention, satisfaction and service delivery factors in healthcare. Focus group discussions are frequently used to obtain a detailed understanding of social issues (Nyumba, Wilson, Derrick, \& Mukherjee, 2018).

\section{Research procedure}

Permission to conduct the study was obtained from the relevant healthcare management. The hard copies of questionnaires were distributed to the respondents in this study. Ethical clearance was obtained prior to commencement of the study. Participant anonymity was achieved by not using any personal details of the respondents in the reporting, and no statement was linked to a particular respondent. Respondents voluntarily participated in the study, and none were forced or coerced to participate. Respondents were also free to discontinue at any stage. Informed consent was sought from each participant before the data collection commenced. Participants were informed about the exact nature and purpose of the research, and they had to read and sign an informed consent form.

\section{Data analyses}

The quantitative data were analysed with SPSS (2018). Descriptive statistics such as frequencies, means, skewness and kurtosis were applied. Exploratory factor analysis was used to determine the factor structure of the measurements. The guideline of $\alpha \geq 0.60$ (see Cortina, 1993) was used in this study to determine the reliability of the measurements. $T$-tests were performed to determine whether any significant differences existed between the two sample groups, based on the measurements. For purposes of this research, Cohen's (1988, p. 283) guidelines for the interpretation of effect sizes were used: 0.0099 constituted a small effect, 0.0588 a medium effect and 0.1379 a large effect. Pearson's correlations were used to test for the significance of relationships between variables. The qualitative data were analysed using thematic content analyses. 


\section{Ethical consideration}

Ethical clearance was obtained prior to commencement of the study from North-West University (clearance number NWU-00224-14-A9).

\section{Results and findings \\ Factor and reliability analyses}

- Work Environment Questionnaire: An exploratory factor analysis was run on the 19-item Work Environment Questionnaire, using the principal component extraction method. The results showed that four factors could be specified. The four factors were labelled as work activities (Factor 1), supervision (Factor 2), development opportunities (Factor 3) and compensation (Factor 4). Five items were deleted because of problematic loadings. The factors explained $60.848 \%$ of the variance.

- General Work Satisfaction Scale: An exploratory factor analysis was run on the three items of the General Work Satisfaction Scale, using the principal component extraction method. The results showed that one factor could be specified. The factor was labelled as general work satisfaction and explained $74.233 \%$ of the variance.

- Employee Satisfaction Scale: An exploratory factor analysis was run on the six items of the Employee Satisfaction Scale, using the principal component extraction method. The results showed that one factor could be specified. Two items were deleted because of problematic loadings. The factor was labelled as employee satisfaction and explained $48.864 \%$ of the variance

- Employee Retention Scale: An exploratory factor analysis was run on the eight items of the Employee Retention Scale using the principal component extraction method. The results showed that one factor could be specified. One item was deleted because of problematic loadings. The factor was labelled as employee satisfaction and explained $54.027 \%$ of the variance.

- Service Delivery Scale: An exploratory factor analysis was run on the six items of the Service Delivery Scale using the principal component extraction method. The results showed that one factor could be specified. Two items were deleted because of problematic loadings. The factor was labelled as service delivery and explained $69.661 \%$ of the variance.

The descriptive statistics and reliabilities of the measurements are presented in Table 1.

From Table 1, it is evident that about $75 \%$ of the respondents were satisfied with their work and believed that they delivered a good-quality service. The respondents reported moderate levels of job satisfaction, turnover intentions, satisfaction with supervision and career development. The results further showed low levels of satisfaction with compensation. The measurements showed usable reliabilities of $\alpha \geq 0.60$ (see Cortina, 1993).

\section{Hypotheses testing}

The next section reports on the testing of the hypotheses for this study. The results of the gap analyses between the mean scores of the urban and rural sample groups are reported in Table 2 .

The results in Table 2 show significant differences between all the measurements, except for supervision. The effects for work activities, compensation, development, work satisfaction, employee retention and service quality were medium. The participants employed in urban areas reported significantly higher levels on all the measurements, except development.

The results in Table 2 partially confirm hypothesis 1 that significant differences exist between urban and rural healthcare workers in terms of the antecedents of employee satisfaction.

Next the results of the hypothesised relationship between the antecedents and employee satisfaction are reported. Pearson correlation analyses were applied. The results are reported in Table 3.

The results in Table 3 show that all the dimensions of Work environment were significantly positively related to General work satisfaction, except for the Supervision dimension for the urban sample group. The effect of Work duties for the urban sample group was large, while the effects of Compensation and Development were medium. All the effects for the rural group were medium. The results in Table 3 show that Work duties, Supervision and Compensation were significantly positively related to Employee satisfaction for the urban sample group. Work duties (medium effect) and Compensation were significantly positively related to Employee satisfaction for the rural sample group.

TABLE 1: Descriptive statistics of the measurements.

\begin{tabular}{lccccc}
\hline Variable & Mean & SD & Skewness & Kurtosis & $\boldsymbol{\alpha}$ \\
\hline Work environment & & & & & \\
Work duties & 3.7130 & 0.68070 & -0.237 & -0.689 & 0.610 \\
Supervision & 3.3975 & 0.87235 & -0.599 & 0.060 & 0.651 \\
Compensation & 2.7037 & 1.01223 & -0.064 & -0.957 & 0.672 \\
Development & 3.1704 & 0.85616 & -0.145 & -0.188 & 0.630 \\
General work satisfaction & 3.8461 & 0.89686 & -1.301 & 3.094 & 0.818 \\
Job satisfaction & 3.4407 & 0.58831 & -0.009 & -0.164 & 0.647 \\
Employee retention & 3.1767 & 0.45227 & -0.419 & 1.256 & 0.853 \\
Service quality & 3.9556 & 0.69086 & -0.493 & -0.285 & 0.847 \\
\hline
\end{tabular}

$\alpha$, Cronbach Alpha; SD, standard deviation.

TABLE 2: Gap analyses between the urban and rural sample group based on the mean scores of the measurements.

\begin{tabular}{lccccc}
\hline Variable & Meanurban & Meanrural & Gap & $\boldsymbol{p}$ & Eta \\
\hline Work activities & 3.7521 & 3.6543 & 0.0977 & $\mathbf{0 . 0 0 5}$ & 0.065 \\
Supervision & 3.2757 & 3.5802 & -0.3045 & 0.372 & 0.024 \\
Compensation & 2.7263 & 2.6698 & 0.0566 & $\mathbf{0 . 0 0 0}$ & 0.108 \\
Development & 3.1632 & 3.1811 & -0.0178 & $\mathbf{0 . 0 0 1}$ & 0.073 \\
Work satisfaction & 3.9300 & 3.7202 & 0.2099 & $\mathbf{0 . 0 0 0}$ & 0.119 \\
Job satisfaction & 3.4486 & 3.4290 & 0.0195 & $\mathbf{0 . 0 3 3}$ & 0.048 \\
Employee retention & 3.2305 & 3.0961 & 0.1343 & $\mathbf{0 . 0 0 0}$ & 0.112 \\
Service quality & 3.9835 & 3.9136 & 0.0700 & $\mathbf{0 . 0 0 1}$ & 0.073 \\
\hline
\end{tabular}

Note: Significant Differences in bold.

Eta, 0 - 0,59, small effect; 0,60-0,12, medium effect; 0,13 and higher large effect. 
Based on the above results, Hypotheses 2, namely, that the antecedents of employee satisfaction are significantly positively related to employee satisfaction, is partially accepted for both the urban sample group and the rural group.

Next, the results of the hypothesised relationship between employee satisfaction and outcome variables (i.e. employee retention and service quality) for urban and rural groups are presented in Table 4. Pearson correlations analyses were applied.

The results in Table 4 show a significant negative relationship between Work satisfaction and Employee retention for both sample groups (medium effects), and a significant positive relationship with Service quality for both sample groups (medium effect for the rural sample group). The results show a significant negative relationship between Employee satisfaction and Employee retention for the urban sample group and a significant positive relationship with Service quality for both sample groups.

The results confirm hypothesis 2 for the urban group that employee satisfaction is significantly negatively related to employee retention. The results further confirm hypothesis 3 for both the urban and rural groups that employee satisfaction is significantly positively related to service quality.

\section{Findings: Focus group session}

Focus group analyses and findings with proof of evidence quotes from participants are reported in the following tables of thematic coding. Table 5 presents the participants' responses to lack of medicine, facilities and work environment.

The thematic codes for the responses regarding lack of recognition and appreciation for their work are presented in Table 6 .

The thematic codes showing participants' frustration with their remuneration, salaries and personal development are shown in Table 7.

One participant revealed that she had thoughts of going overseas, Australia or Saudi Arabia, but that the thought of

\begin{tabular}{|c|c|c|c|c|}
\hline \multirow[t]{2}{*}{ Variable } & \multicolumn{2}{|c|}{ Urban } & \multicolumn{2}{|c|}{ Rural } \\
\hline & $r$ & $p$ & $r$ & $p$ \\
\hline \multicolumn{5}{|c|}{ Work environment and general work satisfaction } \\
\hline Work duties & $0.552 * *$ & 0.000 & $0.364 * *$ & 0.000 \\
\hline Supervision & 0.025 & 0.700 & $0.383 * *$ & 0.000 \\
\hline Compensation & $0.464 * *$ & 0.000 & $0.493 * *$ & 0.000 \\
\hline Development & $0.301 * *$ & 0.000 & $0.462 * *$ & 0.000 \\
\hline \multicolumn{5}{|c|}{ Work environment and job satisfaction } \\
\hline Work duties & $0.145^{*}$ & 0.024 & $0.325 * *$ & 0 \\
\hline Supervision & $0.144 *$ & 0.025 & 0021 & 0.794 \\
\hline Compensation & $0.179 * *$ & 0.005 & $0.162 *$ & 0.039 \\
\hline Development & -0.104 & 0.107 & 0.108 & 0.171 \\
\hline
\end{tabular}

Note: Significant relationships in bold.

*, Practically significant correlation (medium effect): $r \geq 0.30$.

$* *$, Practically significant correlation (large effect): $r \geq 0.50$. being separated from her family was preventing her from doing so. In all focus group sessions, participants knew former friends in the health sector who had left their employment in South Africa for better opportunities in developed countries. They believed that the opportunities in such countries were better because there was evidence of the improvement in the lives of health workers who worked abroad. It was reported that, within a short period after securing employment overseas, their friends had managed to build houses in South Africa, buy cars and live a lavish lifestyle.

However, most of the qualitative findings above indicate dissatisfaction and frustration in the healthcare environment; an interesting counter-finding from the rural female participants was that they valued their rural workplace and environment as they could stay near to their children and serve their community and their people, as is clear from the following quote: 'Our people are happy with the services we provide; Asithembeni uguthi bazoshintsha ngoba be'abantu bagithi [let's hope they do not change]'. This referred to being part of a communal system as is upheld in rural communities within KwaZulu-Natal.

\section{Discussion}

The main objective of this research was to determine the antecedents and outcomes of employee satisfaction for urban and rural healthcare professionals on KwaZulu-Natal. Combined, about $75 \%$ of the respondents were satisfied with their organisation and believed that they delivered a good quality service. The respondents however experienced average levels of job satisfaction relating to their supervisors and career development and low satisfaction with their compensation. In this study, respondents were particularly

TABLE 4: Hypotheses testing: Outcomes of employee satisfaction.

\begin{tabular}{lccccc}
\hline Variable & \multicolumn{2}{c}{ Urban } & & \multicolumn{2}{c}{ Rural } \\
\cline { 2 - 3 } \cline { 5 - 6 } & $\boldsymbol{r}$ & $\boldsymbol{p}$ & & $\boldsymbol{r}$ & $\boldsymbol{P}$ \\
\hline General work satisfaction and outcome variables & & & & \\
General work satisfaction & 0.120 & 0.063 & & 0.113 & 0.152 \\
Employee retention & $-\mathbf{0 . 3 6 7 * *}$ & 0.000 & & $-\mathbf{0 . 3 7 9 * *}$ & 0.000 \\
Service quality & $\mathbf{0 . 2 8 3 ^ { * }}$ & 0.000 & & $\mathbf{0 . 4 1 4 * *}$ & 0.000 \\
Job satisfaction and outcome variables & & & & \\
Employee retention & $-\mathbf{0 . 2 2 5 *}$ & 0.000 & & 0.141 & 0.072 \\
Service quality & $\mathbf{0 . 1 7 3 * *}$ & 0.007 & $\mathbf{0 . 2 5 8 *}$ & 0.001 \\
\hline
\end{tabular}

Note: Significant relationships in bold.

*, Practically significant correlation (medium effect): $r \geq 0.30$.

$* *$, Practically significant correlation (large effect): $r \geq 0.50$.

TABLE 5: Thematic codes from focus group responses regarding availability of medication and equipment.

\begin{tabular}{lll}
\hline Thematic codes - Findings & Properties & $\begin{array}{l}\text { Examples of participants' } \\
\text { responses }\end{array}$ \\
\hline $\begin{array}{l}\text { Lack of facilities/materials } \\
\text { - Possessing the drive to } \\
\text { carry out duties }\end{array}$ & $\begin{array}{l}\text { Concerned about the } \\
\text { availability of medication } \\
\text { and equipment }\end{array}$ & $\begin{array}{l}\text { The medication or } \\
\text { anestheticis finished, and } \\
\text { the hospital is waiting for } \\
\text { delivery. } \\
\text { X-ray machine could not } \\
\text { function; lack of } \\
\text { maintenance }\end{array}$ \\
$\begin{array}{l}\text { Work environment - } \\
\begin{array}{l}\text { Advocating for urgent } \\
\text { attention to the current } \\
\text { situation }\end{array}\end{array}$ & $\begin{array}{l}\text { Being frustrated by the } \\
\text { work environment }\end{array}$ & $\begin{array}{l}\text { There is nothing more } \\
\text { frustrating; } \\
\text { Want to quit this hospital } \\
\text { and } \\
\text { be transferred somewhere }\end{array}$ \\
\hline
\end{tabular}


frustrated with the lack of supervisor recognition for good performance and career advancement. In addition, the participants expressed their dissatisfaction with the fact that they will only get recognition from patients and not their workplace. The results of this study further highlight the continuous problems with supervisor competence in the public healthcare sector (Nkomozana, 2017) as well as poor compensation and recognition of healthcare workers (see Ali \& Wajidi, 2013; Parvin \& Kabar, 2011).

The results of this research showed that significant differences exist between urban and rural groups in terms of the predictors of employee satisfaction (i.e. work activities, compensation and development). The results confirm the findings of previous research by Campbell and Ebuehi (2011) who found that healthcare workers of urban and rural areas differ in terms of the work-related factors that contribute to their job satisfaction. Work duties emerged as the largest significant predictor of employee satisfaction for healthcare workers in the urban areas. In line with the findings of Bhattacharya and Ramachandran (2015), a conducive work environment with the latest state of the art technologies is important for urban healthcare workers to perform their work duties adequately. For healthcare workers, the largest predictors of work satisfaction appeared to be compensation and opportunities for career development. The results

TABLE 6: Thematic codes for focus group response to lack of recognition and appreciation for their work.

\begin{tabular}{|c|c|c|}
\hline Thematic codes & Properties & $\begin{array}{l}\text { Examples of participants' } \\
\text { responses }\end{array}$ \\
\hline \multirow[t]{4}{*}{$\begin{array}{l}\text { Advocating for } \\
\text { recognition }\end{array}$} & \multirow[t]{4}{*}{ Desire for recognition } & $\begin{array}{l}\text { These people should } \\
\text { recognise us; }\end{array}$ \\
\hline & & They don't recognise us; \\
\hline & & $\begin{array}{l}\text { Sometimes, one needs to be } \\
\text { appreciated; }\end{array}$ \\
\hline & & $\begin{array}{l}\text { Give us awards or at least } \\
\text { certificates }\end{array}$ \\
\hline \multirow{2}{*}{$\begin{array}{l}\text { Constantly receiving } \\
\text { positive affirmation } \\
\text { from the patients }\end{array}$} & \multirow{2}{*}{$\begin{array}{l}\text { Seeking recognition from } \\
\text { employer }\end{array}$} & It is as if patients employ us; \\
\hline & & $\begin{array}{l}\text { Instead, you get appreciation } \\
\text { from patients only }\end{array}$ \\
\hline \multirow[t]{4}{*}{$\begin{array}{l}\text { Poor relationship with } \\
\text { supervisors }\end{array}$} & \multirow{4}{*}{$\begin{array}{l}\text { Dissatisfied with the } \\
\text { supervision of the } \\
\text { immediate supervisor and } \\
\text { wanting better work } \\
\text { relations }\end{array}$} & $\begin{array}{l}\text { I wish supervisors would stop } \\
\text { their jealousy; }\end{array}$ \\
\hline & & $\begin{array}{l}\text { When she [supervisor] is } \\
\text { assessing us, she gives us } \\
\text { scores that are questionable; }\end{array}$ \\
\hline & & $\begin{array}{l}\text { My supervisor is not capable } \\
\text { of good supervision; }\end{array}$ \\
\hline & & $\begin{array}{l}\text { Maybe she is bitter that most } \\
\text { of us are furthering our } \\
\text { studies and she is not }\end{array}$ \\
\hline $\begin{array}{l}\text { The need for career } \\
\text { development }\end{array}$ & $\begin{array}{l}\text { Needing recognition and } \\
\text { career development }\end{array}$ & $\begin{array}{l}\text { Patient appreciation can only } \\
\text { bring joy to us, but cannot } \\
\text { contribute to our career } \\
\text { development }\end{array}$ \\
\hline
\end{tabular}

confirm previous studies that indicate the need for increased rewards and benefits as the availability of career development paths and promotion opportunities for healthcare staff in rural areas (Coward et al., 2017). In this study, satisfaction with management support appeared to be a significant predictor for only the rural area group. In line with the finding of Klaas (2007), the importance of supervisor support for rural healthcare workers is emphasised.

The results of this study showed that about $37 \%$ of the respondents considered quitting their jobs. Healthcare workers in urban areas had a significant higher inclination to quit their jobs compared to their counterparts in rural areas. One possible explanation for this finding, and also derived from the qualitative findings, is that healthcare workers in urban areas are more qualified than those in urban areas as a result of their exposure to more opportunities and a better infrastructure. Consequently, it will be easier for them to obtain employment elsewhere.

Some participants from rural areas considered quitting their organisation as a result of access to equipment. Respondents from the focus group sessions experienced that inadequate or damaged equipment hampered their ability to execute their tasks and deliver quality service. Therefore, they would consider seeking employment elsewhere in an environment that allows them to perform their jobs effectively. However, female rural healthcare workers expressed that they would like to stay in their communal area because this way they can stay close to their children and community. As with previous studies, work and job satisfaction were significantly related to the service quality of both urban and rural groups (Deriba et al., 2017). Therefore, the need exists to create adequate infrastructures for healthcare workers where they can deliver quality service (Goetz et al., 2015). Unfortunately, the results of this study continue to emphasise the high turnover intentions of healthcare workers, which in turn threaten the sustainability of the South African healthcare industry.

\section{Practical implications}

The implications of the results for management are that the stakeholders in the healthcare industry need to capacitate the administration of public health institutions to be able to motivate their employees by providing incentives that improve employee satisfaction. A clear policy framework for all the healthcare personnel may help them to realise their full potential. The plan may also need to focus on providing

TABLE 7: Thematic codes for focus group responses showing workers' frustrations.

\begin{tabular}{|c|c|c|}
\hline Thematic codes & Properties & Examples of participants' responses \\
\hline $\begin{array}{l}\text { Having an urgent need for an } \\
\text { adequate remuneration }\end{array}$ & $\begin{array}{l}\text { Being unhappy with } \\
\text { remuneration }\end{array}$ & $\begin{array}{l}\text { The salary is not enough; } \\
\text { I want more money to maintain ingani zami [my children], then okunye kuzolandela [the rest will follow]; } \\
\text { You get paid peanuts; } \\
\text { The salary we receive does not match our social status; } \\
\text { It would have been better if they paid us good salaries; } \\
\text { They don't know our struggles financially; } \\
\text { You do the same job, but another gets paid more; } \\
\text { I would like to earn better; }\end{array}$ \\
\hline $\begin{array}{l}\text { Having the need for professional } \\
\text { development }\end{array}$ & $\begin{array}{l}\text { Needing professional and career } \\
\text { development }\end{array}$ & $\begin{array}{l}\text { There is no professional development; } \\
\text { I think I would rather be empowered in my career than just to earn big money; } \\
\text { There are no career prospects in my job }\end{array}$ \\
\hline
\end{tabular}


incentives for employees in rural settings. These incentives should cater for both the clinical and non-clinical staff.

If a conducive work environment that fosters career development and up-skilling the personnel at the health centres in the rural areas is provided, then aspects such as service delivery would be improved. Furthermore, at the policy level, there may be a need to consider the remuneration of healthcare workers to bring it in line with the nature of their work.

At the policy level, there is also a need to improve the supply of medication and service at the healthcare institutions. The results indicate that the availability of medicines leads to health practitioners being satisfied with their jobs. The policy, therefore, needs to ensure that the health institutions have adequate stocks for treatment of patients.

The study identifies the three primary healthcare system inputs: human resources, physical capital and consumables. As people ultimately deliver all medical services, effective human resources management will play a vital role in the success of health sector reform. This study identified some factors that are critical to the promotion of service delivery within health institutions and employee satisfaction of healthcare employees. The focus of policy-makers and healthcare practitioners should be on enhancing these factors. These factors receiving due attention from policy and management initiatives would lead to employee satisfaction and quality service by employees in the public health sector.

\section{Limitations and recommendations}

This study had some limitations. A cross-sectional research design was followed which limited the research in terms of cause and inferences to be made about the antecedents and outcomes of employee satisfaction in the healthcare sector over the long term. For future research, we recommend longitudinal studies to detect trends in the employee satisfaction of healthcare workers. The sample of this study only included healthcare professionals of KwaZulu-Natal. The results cannot therefore be generalised to healthcare professionals from other South African provinces. Future studies can benefit from expanding this research across the entire healthcare industry in South Africa to allow for more occupation-specific comparisons. The results of the study also lend itself for more in-depth qualitative research to explain the quantitative results in more detail.

\section{Conclusion}

Employee satisfaction has an effect on the quality of services provided in public healthcare institutions. Line management and human resource managers should strive to improve the employee satisfaction determinants in the workplace, such as working conditions, remuneration, availability of medication and equipment, safety and recognition, as these will result in improved quality of services offered to patients. In addition, provision of work-related training, although it is not one of the significant determinants of employee satisfaction, will have a positive impact on the quality of their service.

The results also indicate that the quality of healthcare services in public institutions in rural areas and in clinics is better than those in the urban areas and hospitals in both areas. This is an important finding and shows the need to decongest public hospitals, perhaps through investment in more hospitals. Training more clinical and support staff should be considered as an option for reducing the work overload of health professionals in hospitals and urban public health facilities.

\section{Acknowledgements Competing interests}

The authors declare that they have no financial or personal relationships that may have inappropriately influenced them in writing this article

\section{Authors' contributions}

N.E.B. was the co-supervisor for this study, constructed the article and did the statistical analyses. Y.D.P. was the main supervisor, assisted with the construction of the article and provided editorial inputs. B.T. is a PhD student, collected the data and provided some editorial inputs.

\section{Funding information}

This research received no specific grant from any funding agency in the public, commercial or not-for-profit sectors.

\section{Data availability statement}

Data will be available for ten years as per requirements of North-West University.

\section{Disclaimer}

The views and opinions expressed in this article are those of the authors and do not necessarily reflect the official policy or position of any affiliated agency of the authors.

\section{References}

Adegoke, A.A., Atiyaye, F.B., Abubakar, A.S., Auta, A., \& Aboda, A. (2015). Job satisfaction of midwives in rural Nigeria. Midwifery, 31, 946-956. https://doi. org/10.1016/j.midw.2015.06.010

Ali, R.M., \& Wajidi, F.A. (2013). Factors influencing job satisfaction in Public Healthcare Sector of Pakistan. Global Journal of Management and Business Research Administration and Management, 13(8), 1-7.

Aron, S. (2015). Relationship between Nurses' Job Satisfaction and Quality of Healthcare they deliver. Unpublished Doctoral Thesis, Minnesota State University, Mankato: United States of America.

Aziri, B. (2011). Job satisfaction: A literature review. Management Research and Practice, 3(4), 77-86.

Bakar, C., Akgun, H.S., \& Assaf, A.F. (2007). The role of expectations in patients' hospital assessment: A Turkish hospital example. International Journal of Healthcare Quality Assurance, 21(5), 503-516. https://doi.org/10.1108/09526860810890477

Bhattacharya, I., \& Ramachandran, A. (2015). A path analysis study of retention of healthcare professionals in urban India using health information technology. Human Resources for Health, 13, 1-14. https://doi.org/10.1186/s12960-015-0055-x 
Bonenberger, M., Aikins, M., Akweongo, P., \& Wyss, K. (2014). The effects of healthcare workers motivation and job satisfaction on turnover intention in Ghana: A crossworkenal study. Human Resources for Health, 12, 1-12. https://doi. sectional study. Human Reso
org/10.1186/1478-4491-12-43

Campbell, P.C., \& Ebuehi, O.M. (2011). Job satisfaction: Rural versus urban primary health care workers' perception in Ogun State of Nigeria. West African Journal of Management, 30(6), 408-412.

Clemens, M.A. (2007). Do visas kill? Health effects of African health professional emigration. Unpublished Research paper, Centre for Global Development, Working Paper (114)

Cohen, J. (1988). Statistical power analysis for the behavioral sciences (2nd edn.) Hillsdale, NJ: Lawrence Erlbaum Associates.

Cortina, J.M. (1993). What is coefficient alpha? An examination of theory and applications. Journal of Applied Psychology, 78(1), 98-104. https://doi. org/10.1037/0021-9010.78.1.98

Coustas, E.L. (2019). Factors impacting the retention of registered nurses recruited from India to work in South African hospitals: A case study. International Journal of Africa Nursing Sciences, 10, 6-13. https://doi.org/10.1016/j.ijans.2018.11.003

Coward, R.T., Hogan, T.L., Duncan, R.P., \& Felsen, L.M. (2017). Job satisfaction and nurses employed in rural and long-term care facilities. Research in Nursing and Health, 18(3), 271-284. https://doi.org/10.1002/nur.4770180310

DeMaio, T.J., Rothgeb, J., \& Hess, J. (1998). Improving survey quality through pretesting. Proceedings of the Section on Survey Research Methods, American Statistical Association, 3, 50-58.

Deriba, B.K., Sinke, S.O., Ereso, B.M., \& Badacho, A.S. (2017). Health professionals' job satisfaction and associated at public health centres in West Ethiopia. Human Resources for Health, 15(36), 1-7. https://doi.org/10.1186/s12960-017-0206-3

Field, A. (2018). Discovering statistics using IBM SPSS statistics (5th edn.). London: Sage Publications Ltd.

George, G., Atujuna, M., \& Gow, J. (2013). Migration of South African health workers: The extent to which financial considerations influence internal flows and external movements. BMC Health Services Research, 13(1), 297-304. https://doi. org/10.1186/1472-6963-13-297

Goetz, K., Marx, M., Marx, I., Brodowski, M., Nafula, M., Prytherch, H., ... Szecsenyi, J. (2015). Working atmosphere and job satisfaction of health care staff in Kenya: An exploratory study. BioMed Research International, 1, 1-7. https://doi.org/ $10.1155 / 2015 / 256205$

Gormley, D.K. (2003). Factors affecting job satisfaction in nurse faculty: A metaanalysis. Journal of Nursing Education, 42(4), 174-178.

Grujicic, M., Jovovic-Bata, J., Radjen, S., \& Sipetic-Grujicic, S. (2016). Work motivation and job satisfaction of health workers urban and rural areas. Vojnosanitetskipregled. Military-Medical and Pharmaceutical Review, 73, 62-62. https://doi.org/10.2298/ VSP140715062G

Haskins, J.L., Phakathi, S.A., Grant, M., \& Horwood, C.M. (2017). Factor influencing the recruitment and retention of professional nurses, doctors and allied health professionals in rural hospitals in KwaZulu Natal. Health SA Gesondheid, 22, 174-183. https://doi.org/10.1016/j.hsag.2016.11.002

Heathfield, S.M. (2016). Employee satisfaction: Make employees satisfaction surveys successful. Human Resources. Retrieved from https://www.thebalance.com/ employee-satisfaction-1918014.

International Labour Organisation (2018). World Employment Social Outlook: Trends 2018. International Labour Office - Geneva: ILO.

Jenkins, J.S., Gunst, C., Blitz, J., \& Coetzee, J.F. (2017). What keeps health professionals working in rural district hospitals in South Africa? African Journal of Primary Health Care and Medicine, 7(1), 1-5. https://doi.org/10.4102/phcfm.v7i1.805
Johnson, R.B., Onwuegbuzie, A.J., \& Turner, L.A. (2007). Toward a definition of mixed methods research. Journal of Mixed Methods Research, 1(2), 112-133. https:// doi.org/10.1177/1558689806298224

Kim, J., \& Han, W. (2012). Improving service quality in long-term care hospitals: National evaluation on long-term care hospitals and employees perception of quality dimensions. Osong Public Health and Research Perspectives, 3(2), 94-99. https://doi.org/10.1016/j.phrp.2012.04.005

Klaas, N.P. (2007). Factors influencing the retention of nurses in the rural health facilities of the Eastern Cape. Unpublished Master's dissertation, University of South Africa, Pretoria, South Africa.

Mohase, N., \& Khumal, J. (2014). Job satisfaction in the healthcare services in South Africa: The case of MPH. Mediterranean Journal of Social Sciences, 5(3), 94-102. https://doi.org/10.5901/mjss.2014.v5n3p94

Ngilangwa, D.P., \& Mgomella, G.S. (2018). Factors associated with retention of community health workers in maternal, newborn and child health programme in Simuyu Region, Tanzani. African Journal of Primary Healthcare and Family Medicine, 10(1), 1-8. https://doi.org/10.4102/phcfm.v10i1.1506

Nkomozana, O. (2017). Determining the causes for the shortage of human resources for primary health care in Botswana and developing a pilot intervention to address the problem. Unpublished Doctoral dissertation, Faculty of Medicine and Health Sciences, Stellenbosch University, Cape Town, South Africa.

Nyumba, T.O., Wilson, K., Derrick, C.J., \& Mukherjee, N. (2018). The use of group discussion methodology: Insights of two decades of application in conservation. Special Feature: Qualitative Methods for Eliciting Judgements for Decision Making, 9(9), 20-32. https://doi.org/10.1111/2041-210X.12860

Ogbuabor, D.C., Okonronkwo, I., Uzochukwu, B., \& Onwujekwe, O. (2016) Determinants of job satisfaction and retention of public health care workers in Southeast Nigeria. Journal of Medical Health Development, 21(2), 1-12.

Parvin, M.M., \& Kabir, M.N. (2011). Factors affecting employee job satisfaction of pharmaceutical sector. Australian Journal of Business and Management Research, 1(9), 113-123

Peltier, J., Dahl, A., \& Mulhern, F. (2009). The relationship between employee satisfaction and hospital patient experiences. University of Wisconsin-Whitewater, Northwestern University.

Pillay, Z. (2017). Measures to improve retention of nurses in a KwaZulu-Natal hospital: Nurse managers' views. Unpublished Masters Dissertation, University of South Africa, Pretoria.

Ronen, B., \& Pilskin, J. S. (2006). Focused operations management for health service organisations. San Francisco, CA: Wiley.

Shah, S.K., \& Corley, K.G. (2006). Building better theory by bridging the quantitativequalitative divide. Journal of Management Studies, 43(8), 1821-1835. https://doi. org/10.1111/j.1467-6486.2006.00662.x

Singh, M.M. (2017). Job satisfaction among healthcare professional in public and private healthcare setup in India. Indian Journal of Applied Research, 6(1), 6-8.

SPSS Inc. (2018). SPSS 25 for windows. Chicago, IL: SPSS Inc.

Statistics South Africa (Stats SA). (2015). Statistics South Africa. Retrieved from http:// www.statssa.gov.za.

Tinu, O.C., \& Adeniji, A.A. (2015). Gender influence on job satisfaction and job commitment among colleges of education lecturers. Journal of Education and Practice, 6(13), 159-161.

Whelan, S., Davies, G., Walsh, M., \& Bourke, R. (2010). Public sector corporate branding and customer orientation. Journal of Business Research, 63(11), 1164-1171. https://doi.org/10.1016/j.jbusres.2009.10.013 